\title{
Efficient polygalacturonase production from agricultural and agro-industrial residues by solid-state culture of Aspergillus sojae under optimized conditions
}

\author{
Doreen Heerd, Sonja Diercks-Horn and Marcelo Fernández-Lahore*
}

\begin{abstract}
Previously identified fungal pectinase producers of the species Aspergillus sojae were used for optimization of polygalacturonase production in solid-state fermentation applying Design of Experiment. The effects of media composition and several process parameters, like inoculum size, moisture level, incubation time and temperature on polygalacturonase activity were studied in screening and optimization investigations. Utilization of agricultural and agro-industrial by-products provided the establishment of a cost-efficient and sustainable process for enzyme production. Comparison of pectinase production by A. sojae ATCC 20235 and A. sojae CBS 100928 under optimized conditions yielded 6.9 times higher polygalacturonase activity by A. sojae ATCC 20235. Highest enzyme yield (909.5 $\pm 2.7 \mathrm{U} / \mathrm{g}$ ) was obtained by A. sojae ATCC 20235 after 8 days at $30^{\circ} \mathrm{C}$ applying $30 \%$ sugar beet pulp as inducer substrate in combination with wheat bran as medium wetted at $160 \%$ with $0.2 \mathrm{M} \mathrm{HCl}$. Furthermore, an overview of pectinolytic enzyme activities present in the extracts of both strains is provided. Protein profiles of both strains are given by SDS-PAGE electrophoresis, as well as zymograms for pectinolytic enzymes in comparison to commercial pectinase preparations.
\end{abstract}

Keywords: Polygalacturonase; Aspergillus sojae; Design of Experiment; Solid-state fermentation; Agro-industrial residues

\section{Background}

The biotechnological potential of pectinolytic enzymes is well known due to their various industrial applications wherever degradation of pectic substances is required. This includes food related processes like fruit juice clarification, tissue maceration, wine clarification, coffee and tea fermentation and many others (Kashyap et al. 2001). It has been reported that pectinases have a share of almost $5 \%$ of global enzyme sales (Alimardani-Theuil et al. 2011). Commercial pectinases used in food industry normally contain a mixture of enzymes that split pectic compounds; which traditionally includes PG (polygalacturonase), PL (pectin lyase) and PME (pectin methylesterase) (Del Cañizo et al. 1994). Pectinolytic enzyme production occupies about $10 \%$ of the worldwide manufacturing of enzyme preparations (Semenova et al.

\footnotetext{
* Correspondence: m.fernandez-lahore@jacobs-university.de Downstream Processing Laboratory, Jacobs University Bremen gGmbH, Campus Ring 1, 28759 Bremen, Germany
}

2006). Industrial production of microbial pectinolytic enzymes is mainly done by filamentous fungi, especially Aspergillus niger (Naidu and Panda 1998). Aspergillus species produce a large number of enzymes particularly involved in the degradation of pectic substances (van den Brink and de Vries 2011). However, the variety of enzyme sets differs between fungal species (Benoit et al. 2012).

The koji molds, Aspergillus oryzae and Aspergillus sojae, are often associated with a long history of safe use in traditional food fermentations and several Aspergillus-derived food additive products have already obtained a GRAS (generally recognized as safe) status from regulatory authorities (Heerikhuisen et al. 2005, Jørgensen 2007), which supports the potential of these strains as production organisms for pectinolytic enzymes used in food industry.

Filamentous fungi are known to produce pectinolytic enzymes in submerged fermentation (SmF), as well as in solid-state fermentation (SSF) processes. They are capable 
of synthesizing and secreting large quantities of certain proteins into the extracellular medium. Degradation and utilization of diverse biopolymers such as starch, cellulose or pectin enables cultivation of Aspergillus species on agricultural and agro-industrial residues, which can be used as low-cost substrates for microbial enzyme production in SSF processes (Nigam and Pandey 2009). The application of agricultural and agro-industrial by-products, such as apple pomace or sugar beet pulp, offers a wide range of alternative substrates and helps to solve disposal problems of these by-products. The apple pomace is mainly composed of insoluble carbohydrates such as cellulose, hemicelluloses and lignin. Traditionally, apple pomace and citrus peels are used as raw materials for pectin production. Citrus peels consist of approximately $24 \%$ of pectic substances on $\alpha$-D-galacturonic acid basis (Yapo et al. 2007). Alternatively, high content in pectins (20-25\%), its availability and low-cost make sugar beet pulp a potential source of pectins. Sugar beet pulp is mainly composed of (\% on dry basis) pectin, 28.7; cellulose, 20; hemicellulose, 17.5; protein, 9.0; and lignin 4.4 (Jacob 2009). Since the pectin content of beet pulp or apple pomace is high it can be used for the microbial production of pectinolytic enzymes without adding pectinaceous material as inducer. However, the most potent solid agro-industrial by-product for biotechnological pectinolytic enzyme production, used in combination or without pectinase inducers, is wheat bran, which is composed predominantly of non-starch carbohydrates, starch and crude proteins (Jacob 2009).

Utilization of low-cost agro-industrial residues offers potential benefits for SSF, which is attractive for implementation of sustainable bioprocesses. Further advantages of SSF processes are lower energy requirement associated with higher product yields and less wastewater production with lesser risk of bacterial contamination. Nevertheless, there are many factors which have a critical influence on the process development in SSF, such as selection of microorganism and substrate or optimum physicalchemical and biological process parameters (Thomas et al. 2013). In view of this, optimization of the SSF process for PG production by $A$. sojae was targeted applying statistical design tools.

A previous study demonstrated already the potential of $A$. sojae for pectinase production in SSF (Heerd et al. 2012). A further study about application of strain improvement methods revealed the increase of pectinase production by $A$. sojae applying a classical mutation and selection strategy (Heerd et al. 2014). The present study describes the SSF process optimization for enhancing the pectic acid-degrading activity, which is referred to as PG activity, using statistical design techniques. Response surface methodology (RSM) was applied for optimization of SSF utilizing agricultural and agro-industrial by-products as commercial substrates for the establishment of a sustainable bioprocess. Carbohydrate active enzymes of the pectinase enzyme-complex were investigated comparing the production by two fungal strains of $A$. sojae under optimized conditions and characterizing the pectinolytic enzyme sets on the basis of their substrate degrading mode.

\section{Materials and methods \\ Materials}

Dried bitter orange peel (Cortex Aurantii Fructus amar. conc.) was purchased from Heinrich Klenk GmbH \& Co. KG (Schwebheim, Germany) and was ground to small particles (of varied size) in a coffee mill. Nordzucker AG (Uelzen, Germany) provided two different kinds of sugar beet pulp pellets: molassed (with approximately $30 \%$ molasses) and unmolassed. Pelletized pulp (dry matter $>89 \%$ ) was ground to small particles due to easier handling in SSF on laboratory scale. Apple pomace, a by-product from processing apples, was a heterogeneous mixture of different kinds of apples, like Elstar, Jonagold, Jonagored or Braeburn and was obtained from Döhler $\mathrm{GmbH}$ (Neuenkirchen, Germany). It had a moisture content of approximately $73 \%$ (moisture content on wet-basis), determined by drying at $105^{\circ} \mathrm{C}$ until constant weight. All by-products in this study were used in combination with wheat bran, which was obtained as fine bran $(90 \%<630 \mu \mathrm{m})$ from Bremer Rolandmühle Erling $\mathrm{GmbH}$ \& Co. KG (Bremen, Germany).

All chemicals were purchased from AppliChem GmbH (Darmstadt, Germany), except dithiothreitol (DTT) was purchased from Carl Roth GmbH \& CO. KG (Karlsruhe, Germany). Substrates for detection of pectinolytic activities, e.g. pectin, polygalacturonic acid and polygalacturonic acid sodium salt, as well as the chemical sodium arsenate dibasic heptahydrate, and pectinase from $A$. niger were purchased from Sigma-Aldrich Chemie $\mathrm{GmbH}$ (Steinheim, Germany). Fructozym P was obtained from ERBSLÖH Geisheim AG (Geisheim, Germany).

\section{Microorganisms}

A. sojae CBS 100928 was obtained from the Centraalbureau voor Schimmelcultures (CBS) (Utrecht, Netherlands) and A. sojae ATCC 20235 was provided by İzmir Institute of Technology, İzmir, Turkey. Propagation was done on agar plates according to the specifications given in Heerd et al. (2012). It has to be noted that A. sojae ATCC 20235, which is still deposited as $A$. sojae at the American Type of Culture Collection (ATCC), did not meet the requirements to be classified as $A$. sojae on the basis of morphological parameters (Ushijima et al. 1982), and has been reclassified as $A$. oryzae based on the alpA restriction fragment length polymorphism (RFLP) (Heerikhuisen et al. 2005). 


\section{Inoculum}

The spore suspensions used as inoculum were obtained from molasses agar slants containing: glycerol $(45 \mathrm{~g} / \mathrm{L})$, molasses $(45 \mathrm{~g} / \mathrm{L})$, peptone $(18 \mathrm{~g} / \mathrm{L}), \mathrm{NaCl}(5 \mathrm{~g} / \mathrm{L}), \mathrm{KCl}$ $(0.5 \mathrm{~g} / \mathrm{L}), \mathrm{FeSO}_{4} \cdot 7 \mathrm{H}_{2} \mathrm{O}(15 \mathrm{mg} / \mathrm{L}), \mathrm{KH}_{2} \mathrm{PO}_{4}(60 \mathrm{mg} / \mathrm{L})$, $\mathrm{MgSO}_{4}(50 \mathrm{mg} / \mathrm{L}), \mathrm{CuSO}_{4} \cdot 5 \mathrm{H}_{2} \mathrm{O}(12 \mathrm{mg} / \mathrm{L}), \mathrm{MnSO}_{4}$. $\mathrm{H}_{2} \mathrm{O}(15 \mathrm{mg} / \mathrm{L})$ and agar $(20 \mathrm{~g} / \mathrm{L})$. Slants were incubated at $30^{\circ} \mathrm{C}$ for 1 week. Spores were harvested from the slants using sterile Tween 80 water $(0.02 \%)$ and counted in a Thoma counting chamber to adjust the spore concentrations according to the experimental design (see section Experimental Design).

\section{Culture medium and growth conditions}

SSF was performed in 300-mL culture flasks containing $10 \mathrm{~g}$ solid media wetted with diluted $\mathrm{HCl}$ at the respective concentrations according to the experimental design. The described moisture levels in all experimental set-ups were calculated as dry basis moisture content as described in Heerd et al. (2014). Culture flasks containing the wetted media were sterilized at $121^{\circ} \mathrm{C}$ for $20 \mathrm{~min}$. Flasks were inoculated with $1 \mathrm{~mL}$ of spore suspension containing the desired amount of total spores and incubated according to the experimental design (see section Experimental Design).

\section{Experimental design}

Experiments were designed and evaluated utilizing the MODDE 9.0 software package, supplied by Umetrics AB, Umeå, Sweden. Exo-PG activity was the response value in all experimental setups.

\section{PG production by A. sojae ATCC 20235}

In the screening part of this study the effects of temperature $\left(\mathrm{X}_{\mathrm{T}}\right)$, inoculum size $\left(\mathrm{X}_{\mathrm{Is}}\right)$, time $\left(\mathrm{X}_{\mathrm{t}}\right), \mathrm{HCl}$ concentration $\left(\mathrm{X}_{\mathrm{HCl}}\right)$ and inducer substrate $\left(\mathrm{X}_{\mathrm{S}}\right)$ on $\mathrm{PG}$ production were investigated using a complemented D-optimal design with two replicated center-points of each inducer substrate, giving a total number of 24 trials (Table 1). An estimate of the main effect was obtained by evaluating the difference in process performance caused by a change from the low to the high levels of the corresponding variable. The moisture content was fixed at $120 \%$.

A $2^{4}$ full factorial design with two replicated centerpoints for each of the two selected inducer substrates (sugar beet pulp and apple pomace), giving a total of 20 trials, was used to further explore the effects of the two inducer substrates and three more variables (inducer concentration, $\mathrm{HCl}$ concentration and time) (Table 2). Experiments were conducted at $28^{\circ} \mathrm{C}$ applying a moisture level of $120 \%$ and an inoculum size of $2 \times 10^{7}$ spores per trial.
In the optimization part, the settings of the two variables inducer concentration $\left(\mathrm{X}_{\mathrm{S}}\right)$ and moisture level $\left(\mathrm{X}_{\mathrm{M}}\right)$ were optimized using an experimental design, which was completed by manual addition of 7 trials to a D-optimal design for identification of the optimal region, giving a total of 18 trials (Table 3). Experiments were conducted at $28^{\circ} \mathrm{C}$ for 5 days with a total amount of $2 \times 10^{7}$ spores per flask.

Applying the optimized medium composition of $30 \%$ inducer substrate and a moisture level of $160 \%$, the process parameters time $\left(\mathrm{X}_{\mathrm{t}}\right)$ and temperature $\left(\mathrm{X}_{\mathrm{T}}\right)$ were optimized using D-optimal design due to the manual addition of 3 experimental runs, giving a total of 14 trials, which were inoculated with $2 \times 10^{7}$ spores per trial (Table 4).

\section{PG production by $A$. sojae CBS 100928}

In the screening part, the effects of moisture level $\left(\mathrm{X}_{\mathrm{M}}\right)$, time $\left(\mathrm{X}_{\mathrm{t}}\right)$ and temperature $\left(\mathrm{X}_{\mathrm{T}}\right)$ on PG production by $A$. sojae CBS 100928 were studied using a full factorial design. The central points were performed in duplicate at the low and high level of the variable temperature due to the narrow temperature range, giving a total of 12 trials (Table 5).

For optimization of the settings of two selected variables from the factorial design, moisture level $\left(\mathrm{X}_{\mathrm{M}}\right)$ and time $\left(\mathrm{X}_{\mathrm{t}}\right)$, a central composite face-centered (CCF) design with three replicates at the central point was applied, giving a total of 11 trials (Table 6).

Following the findings for culturing conditions of $A$. sojae ATCC 20235, all experimental runs were inoculated with $2 \times 10^{7}$ spores of $A$. sojae CBS 100928 per trial.

\section{Enzyme leaching and protein estimation}

At the end of cultivation, the enzyme recovery was obtained by adding $50 \mathrm{~mL}$ distilled water into each flask and mixing in an incubator shaker (Innova 4230, New Brunswick Scientific) at $350 \mathrm{rpm}, 24^{\circ} \mathrm{C}$, for $60 \mathrm{~min}$. The extract was separated from the fermented substrate by centrifugation at $4^{\circ} \mathrm{C}, 3220 \times \mathrm{g}$, for $30 \mathrm{~min}$. Enzyme activities and total protein concentration were determined in the supernatant.

Total extracellular protein content was measured according to the modified Bradford's method (Bradford 1976), using the Coomassie Plus ${ }^{\text {TM }}$ Protein Assay Kit (Pierce, Fischer scientific, Schwerte, Germany). The assay was performed in a microplate by detecting the absorbance at $595 \mathrm{~nm}$ using bovine serum albumin (BSA) as a standard. Soluble protein content was expressed as milligram per gram dry substrate $(\mathrm{mg} / \mathrm{g})$.

\section{Exo-pectinolytic activity measurement Polygalacturonase assay}

Exo-PG activity was assayed according to the procedure provided by Panda et al. (1999) with slight modifications 
Table 1 D-optimal design and experimental results of exo-PG activity in the first screening step of A. sojae ATCC 20235

\begin{tabular}{|c|c|c|c|c|c|c|}
\hline & \multicolumn{5}{|c|}{ Experimental factors } & \multirow{2}{*}{$\begin{array}{c}\text { Response } \\
\text { exo-PG activity }(U / g)\end{array}$} \\
\hline & Inducer substrate & Temperature $\left({ }^{\circ} \mathrm{C}\right)$ & Inoculum (Total spores) & Time (d) & $\mathrm{HCl}$ concentration $(\mathrm{mM})$ & \\
\hline 1 & Orange peel & 32 & $3 \times 10^{7}$ & 3 & 50 & 30.3 \\
\hline 2 & Orange peel & 32 & $3 \times 10^{7}$ & 5 & 50 & 21.5 \\
\hline 3 & Orange peel & 24 & $10^{4}$ & 3 & 300 & - \\
\hline 4 & Orange peel & 24 & $10^{4}$ & 5 & 300 & - \\
\hline 5 & Apple pomace & 24 & $10^{4}$ & 3 & 50 & 20.0 \\
\hline 6 & Apple pomace & 32 & $10^{4}$ & 3 & 50 & 20.1 \\
\hline 7 & Apple pomace & 24 & $3 \times 10^{7}$ & 5 & 300 & 216.3 \\
\hline 8 & Apple pomace & 32 & $3 \times 10^{7}$ & 5 & 300 & 223.8 \\
\hline 9 & Sugar beet pulp & 24 & $3 \times 10^{7}$ & 3 & 50 & 58.5 \\
\hline 10 & Sugar beet pulp & 32 & $10^{4}$ & 5 & 50 & 94.9 \\
\hline 11 & Sugar beet pulp & 24 & $3 \times 10^{7}$ & 3 & 300 & - \\
\hline 12 & Sugar beet pulp & 32 & $10^{4}$ & 5 & 300 & - \\
\hline 13 & Sugar beet with molasses & 24 & $10^{4}$ & 5 & 50 & 76.7 \\
\hline 14 & Sugar beet with molasses & 24 & $3 \times 10^{7}$ & 5 & 50 & 30.5 \\
\hline 15 & Sugar beet with molasses & 32 & $10^{4}$ & 3 & 300 & - \\
\hline 16 & Sugar beet with molasses & 32 & $3 \times 10^{7}$ & 3 & 300 & - \\
\hline $17-18^{*}$ & Orange peel & 28 & $1,5 \times 10^{7}$ & 4 & 175 & $140.3 \pm 3.8$ \\
\hline $19-20^{*}$ & Apple pomace & 28 & $1,5 \times 10^{7}$ & 4 & 175 & $243.0 \pm 10.3$ \\
\hline $21-22^{*}$ & Sugar beet pulp & 28 & $1,5 \times 10^{7}$ & 4 & 175 & $407.5 \pm 13.9$ \\
\hline $23-24^{*}$ & Sugar beet with molasses & 28 & $1,5 \times 10^{7}$ & 4 & 175 & $291.2 \pm 1.7$ \\
\hline
\end{tabular}

*The standard variation between the values of each center point repetition was below $5 \%$.

as described in Heerd et al. (2014). One unit of exo-PG activity was defined as the amount of enzyme that catalyzes the release of $1 \mu \mathrm{mol}$ of galacturonic acid per unit volume of supernatant per minute under the applied assay conditions. Exo-PG activity was expressed as unit per gram dry substrate $(\mathrm{U} / \mathrm{g})$.

\section{Polymethylgalacturonase Assay}

Exo-PMG activity was determined according to the method provided by Blandino et al. (2002) with slight modifications, as previously described in Heerd et al. (2012). One unit of exo-PMG activity was defined as the amount of enzyme that catalyses the release of $1 \mu \mathrm{mol}$ of galacturonic acid per unit volume of supernatant per minute under the applied assay conditions. Exo-PMG activity was expressed as unit per gram dry substrate (U/g).

\section{Endo-pectinolytic activity measurement}

Endo-enzyme activities were determined by measuring the decrease in viscosity of a substrate solution, either $2 \%(\mathrm{w} / \mathrm{v})$ pectin for endo-PMG or $3.2 \%(\mathrm{w} / \mathrm{v})$ polygalacturonic acid (sodium salt) for endo-PG. Reduction in viscosity was determined according to a method of Mill and Tuttobello (1961), utilizing a graduated glass pipette as viscometer, which was modified as described in Heerd et al. (2014). The applied sample concentration was adjusted to $1 \mathrm{U} / \mathrm{mL}$ of exo-PG activity and the incubation time was reduced to $5 \mathrm{~min}$ at $40^{\circ} \mathrm{C}$. One unit of endopectinase activity (either PG or PMG) was defined according to Patil and Dayanand (2006) as the quantity of enzyme, which caused a $50 \%$ reduction in viscosity of the reaction mixture per minute, under the applied assay conditions. Endo-pectinolytic activities were expressed as unit per milliliter crude extract $(\mathrm{U} / \mathrm{mL})$.

\section{Plate assay for proteolytic activity measurement}

Dual-substrate assay plates were prepared according to the procedure given by Montville (1983), containing 1\% $(\mathrm{w} / \mathrm{v})$ casein and $1 \%(\mathrm{w} / \mathrm{v})$ gelatin as substrates. Wells of $5 \mathrm{~mm}$ diameter were cut into the solid media and filled with $30 \mu \mathrm{L}$ crude extract or commercial pectinase solutions. After $24 \mathrm{~h}$ incubation at $30^{\circ} \mathrm{C}$ the diameters of the zones formed were measured. Zone diameters (D) were converted to $\log _{10}$ adjusted zone area by the following expression:

$$
\log _{10} \text { adjusted zone area }=\log _{10}\left[(\mathrm{D} / 2)^{2} \pi-(5.0 / 2)^{2} \pi\right]
$$

Proteolytic activity was reported in this manner and referred to as zone area $\left(\log _{10} \mathrm{~mm}^{2}\right)$. 
Table 2 Full factorial design and experimental results of exo-PG activity in the second screening step of $A$. sojae ATCC 20235

\begin{tabular}{|c|c|c|c|c|c|}
\hline \multirow[t]{2}{*}{ Trial } & \multicolumn{4}{|c|}{ Experimental factors } & \multirow{2}{*}{$\begin{array}{c}\text { Response } \\
\text { exo-PG activity }(U / g)\end{array}$} \\
\hline & Inducer substrate & Inducer concentration (\%) & $\mathrm{HCl}$ concentration $(\mathrm{mM})$ & Time (d) & \\
\hline 1 & Apple pomace & 10 & 0.1 & 3.5 & 28.8 \\
\hline 2 & Sugar beet pulp & 10 & 0.1 & 3.5 & 68.2 \\
\hline 3 & Apple pomace & 40 & 0.1 & 3.5 & 57.5 \\
\hline 4 & Sugar beet pulp & 40 & 0.1 & 3.5 & 104.2 \\
\hline 5 & Apple pomace & 10 & 0.22 & 3.5 & 209.5 \\
\hline 6 & Sugar beet pulp & 10 & 0.22 & 3.5 & 300.4 \\
\hline 7 & Apple pomace & 40 & 0.22 & 3.5 & 165.5 \\
\hline 8 & Sugar beet pulp & 40 & 0.22 & 3.5 & - \\
\hline 9 & Apple pomace & 10 & 0.1 & 5.5 & 4.3 \\
\hline 10 & Sugar beet pulp & 10 & 0.1 & 5.5 & 12.5 \\
\hline 11 & Apple pomace & 40 & 0.1 & 5.5 & 38.1 \\
\hline 12 & Sugar beet pulp & 40 & 0.1 & 5.5 & 88.8 \\
\hline 13 & Apple pomace & 10 & 0.22 & 5.5 & 91.7 \\
\hline 14 & Sugar beet pulp & 10 & 0.22 & 5.5 & 374.5 \\
\hline 15 & Apple pomace & 40 & 0.22 & 5.5 & 225.2 \\
\hline 16 & Sugar beet pulp & 40 & 0.22 & 5.5 & - \\
\hline $17-18^{*}$ & Apple pomace & 25 & 0.16 & 4.5 & $118.2 \pm 5.4$ \\
\hline $19-20^{*}$ & Sugar beet pulp & 25 & 0.16 & 4.5 & $277.5 \pm 1.7$ \\
\hline
\end{tabular}

*The standard variation between the center point repetitions was below $5 \%$.

\section{Protein pattern analysis}

The crude extracts were dialyzed against distilled water over night at $4^{\circ} \mathrm{C}$, using SnakeSkin ${ }^{\oplus}$ pleated dialysis tubing, 10,000 MWCO (Thermo Scientific, Rockford, USA). Samples were concentrated to $1.5 \mathrm{mg} / \mathrm{mL}$ total protein concentration, using a freeze-dryer.

\section{One-dimensional electrophoresis}

SDS-PAGE was performed according to the method of Laemmli (1970) as described previously (Heerd et al. 2012). Protein bands were visualized, using colloidal Coomassie (G-250) staining (Neuhoff et al. 1988).

\section{Native polyacrylamide gel electrophoresis/zymogram}

Native PAGE was performed by excluding SDS and DTT from the electrophoresis protocol described above. The "sandwich" method was used to detect the activity of pectinases acting on polygalacturonic acid sodium salt as substrate (Manchenko 1994). Briefly, proteins were separated on a native PAGE and subsequently the gel was first incubated for $20 \mathrm{~min}$ in $0.1 \mathrm{M}$ citrate phosphate buffer ( $\mathrm{pH}$ 5.0) and afterwards contacted with an (solid) agar substrate containing $0.25 \%(\mathrm{w} / \mathrm{v})$ polygalacturonic acid sodium salt for $50 \mathrm{~min}$ and for $90 \mathrm{~min}$ at $30^{\circ} \mathrm{C}$ (in $80 \%$ humidity chamber). The agar plate was then treated with $1 \%(\mathrm{w} / \mathrm{v})$ cetyltrimethylammonium bromide which precipitated the substrate and revealed pectinase activity as translucent bands on an opaque background.

\section{Statistical analysis}

The software MODDE 9.0 (Umetrics AB, Umeå, Sweden) was used to build and analyze the experimental designs. The mathematic-statistical treatment of the obtained experimental data through the fit of a polynomial function was followed by the evaluation of the model's fitness, e.g. the two companion statistics, goodness of fit $\left(\mathrm{R}^{2}\right)$ and goodness of prediction $\left(\mathrm{Q}^{2}\right)$ were applied. Furthermore, analysis of variance (ANOVA) was used to evaluate the results for enzymatic activity shown for experimental designs (level of $95 \%$ of confidence $p<0.05$ ) and evaluation of the model residuals was done using a normal probability plot for detecting deviation experiments. The PG production was analyzed by using a second-order polynomial regression equation for explaining the behavior of the system in optimization experiments.

$$
Y=\beta_{0}+\sum_{i=1}^{k} \beta_{i} X_{i}+\sum_{i=1}^{k} \beta_{i i} X_{i}^{2}+\sum_{i} \sum_{j} \beta_{i j} X_{i} X_{j}+\varepsilon
$$

where $\mathrm{Y}$ is the predicted response, $\mathrm{k}$ is the number of factor variables, $\beta_{0}$ the model constant, $\beta_{i}$ the linear coefficients, $X_{i}$ the independent factor variables, $\beta_{\mathrm{ii}}$ the quadratic coefficients, $\beta_{\mathrm{ij}}$ the interaction coefficients and 
Table 3 D-optimal design and experimental results of exo-PG activity in the medium optimization for $A$. sojae ATCC 20235

\begin{tabular}{|c|c|c|c|}
\hline \multirow[t]{2}{*}{ Trial } & \multicolumn{2}{|c|}{ Experimental factors } & \multirow{2}{*}{$\begin{array}{c}\text { Response } \\
\text { exo-PG activity }(\mathrm{U} / \mathrm{g})\end{array}$} \\
\hline & $\begin{array}{c}\text { Inducer } \\
\text { concentration (\%) }\end{array}$ & $\begin{array}{l}\text { Moisture } \\
\text { level (\%) }\end{array}$ & \\
\hline 1 & 10 & 85 & 124.1 \\
\hline 2 & 35 & 85 & 270.1 \\
\hline 3 & 10 & 135 & 371.2 \\
\hline 4 & 35 & 135 & 552.3 \\
\hline 5 & 10 & 110 & 252.4 \\
\hline 6 & 35 & 110 & 413.5 \\
\hline 7 & 22.5 & 85 & 221.9 \\
\hline 8 & 22.5 & 135 & 493.6 \\
\hline $9^{*}$ & 22.5 & 110 & 347.5 \\
\hline $10^{*}$ & 22.5 & 110 & 328.5 \\
\hline $11^{*}$ & 22.5 & 110 & 325.4 \\
\hline 12 & 65 & 165 & 0 \\
\hline 13 & 65 & 145 & 0 \\
\hline 14 & 45 & 165 & 512.4 \\
\hline 15 & 45 & 145 & 418.7 \\
\hline 16 & 55 & 155 & 39.5 \\
\hline 17 & 65 & 135 & 0 \\
\hline 18 & 35 & 165 & 557.2 \\
\hline
\end{tabular}

*The standard variation between the center point repetitions was below $3 \%$.

Table 4 D-optimal design and experimental results of exo-PG activity in the process optimization for $A$. sojae ATCC 20235

\begin{tabular}{|c|c|c|c|}
\hline \multirow[t]{2}{*}{ Trial } & \multicolumn{2}{|c|}{ Experimental factors } & \multirow{2}{*}{$\begin{array}{c}\text { Response } \\
\text { exo-PG activity }(\mathrm{U} / \mathrm{g})\end{array}$} \\
\hline & Time (d) & Temperature $\left({ }^{\circ} \mathrm{C}\right)$ & \\
\hline 1 & 5 & 26 & 496.0 \\
\hline 2 & 7 & 26 & 603.1 \\
\hline 3 & 5 & 34 & 306.7 \\
\hline 4 & 7 & 34 & 532.4 \\
\hline 5 & 5 & 30 & 586.2 \\
\hline 6 & 7 & 30 & 678.2 \\
\hline 7 & 6 & 26 & 614.0 \\
\hline 8 & 6 & 34 & 390.5 \\
\hline $9^{*}$ & 6 & 30 & 619.4 \\
\hline $10^{*}$ & 6 & 30 & 705.3 \\
\hline $11^{*}$ & 6 & 30 & 680.3 \\
\hline 12 & 8 & 26 & 693.9 \\
\hline 13 & 8 & 30 & 847.3 \\
\hline 14 & 8 & 34 & 651.0 \\
\hline
\end{tabular}

*The standard variation between the center point repetitions was below $10 \%$.
Table 5 Full factorial design and experimental results of exo-PG activity in the screening step of $A$. sojae CBS 10928

\begin{tabular}{|c|c|c|c|c|}
\hline \multirow[t]{2}{*}{ Trial } & \multicolumn{3}{|c|}{ Experimental factors } & \multirow{2}{*}{$\begin{array}{c}\text { Response } \\
\text { exo-PG } \\
\text { activity (U/g }\end{array}$} \\
\hline & $\begin{array}{l}\text { Moisture } \\
\text { level (\%) }\end{array}$ & Temperature $\left({ }^{\circ} \mathrm{C}\right)$ & Time (d) & \\
\hline 1 & 80 & 24 & 4 & 23.6 \\
\hline 2 & 160 & 24 & 4 & 36.4 \\
\hline 3 & 80 & 30 & 4 & 31.6 \\
\hline 4 & 160 & 30 & 4 & 39.6 \\
\hline 5 & 80 & 24 & 8 & 33.9 \\
\hline 6 & 160 & 24 & 8 & 106.0 \\
\hline 7 & 80 & 30 & 8 & 34.1 \\
\hline 8 & 160 & 30 & 8 & 104.2 \\
\hline $9-10^{*}$ & 120 & 24 & 6 & $69.8 \pm 1.8$ \\
\hline $11-12^{*}$ & 120 & 30 & 6 & $108.1 \pm 5.9$ \\
\hline
\end{tabular}

$\varepsilon$ is the error factor. The graphical presentation of the polynomial equation in the form of contour plots was used to describe the individual and cumulative effects of the factors on PG production and was obtained via the MODDE 9.0 software as well.

\section{Results and discussion}

\section{PG production by A. sojae ATCC 20235}

Results of the first screening investigation are presented in Table 1, exploring the effect of several inducer substrates, inoculum size, temperature, cultivation time and $\mathrm{HCl}$ concentration on PG production with a complemented D-optimal design $\left(R^{2} / Q^{2} 0.88 / 0.71\right)$. The exo-PG activities varied significantly depending on the applied cultivation

Table 6 Central composite face-centered design and experimental results of exo-PG activity in the optimization step of $A$. sojae CBS 100928

\begin{tabular}{|c|c|c|c|}
\hline \multirow[t]{2}{*}{ Trial } & \multicolumn{2}{|c|}{ Experimental factors } & \multirow{2}{*}{$\begin{array}{c}\text { Response } \\
\text { exo-PG activity }(U / g)\end{array}$} \\
\hline & Moisture level (\%) & Time (d) & \\
\hline 1 & 130 & 6 & 87.5 \\
\hline 2 & 170 & 6 & 49.7 \\
\hline 3 & 130 & 8 & 95.5 \\
\hline 4 & 170 & 8 & 95.7 \\
\hline 5 & 130 & 7 & 94.7 \\
\hline 6 & 170 & 7 & 63.2 \\
\hline 7 & 150 & 6 & 94.0 \\
\hline 8 & 150 & 8 & 120.7 \\
\hline $9^{*}$ & 150 & 7 & 93.8 \\
\hline $10^{*}$ & 150 & 7 & 103.4 \\
\hline $11^{*}$ & 150 & 7 & 102.0 \\
\hline
\end{tabular}


conditions. Trials performed at high level of $\mathrm{HCl}$ concentration resulted in no activity due to the repression of fungal growth, with the exception of experiments utilizing apple pomace as inducer substrate. These trials without fungal growth have been excluded for analysis. The ANOVA results indicated that the most important factors affecting exo-PG activity were the inducer substrates sugar beet pulp and apple pomace as well as the factor $\mathrm{HCl}$ concentration. The high moisture content in apple pomace (73\%) diluted the total $\mathrm{HCl}$ concentration in the medium. In general, acidic $\mathrm{pH}$ treatment of media is advantageous in SSF processes applying fungi, due to their tolerance towards low $\mathrm{pH}$-values, which is minimizing the risk of contamination during cultivation. Moreover, many fungi secrete PG in acidic media and this is also the $\mathrm{pH}$ range where majority of their PGs show optimum catalytic activity (Niture 2008).

Maximal PG activity of $407.5 \pm 13.9 \mathrm{U} / \mathrm{g}$ was obtained at the center points of the experimental setup using sugar beet pulp as inducer substrate, which was 1.4 times superior to activities obtained with molassed sugar beet pulp. SSF processes are known to overcome the effect of catabolite repression (Nandakumar et al. 1999, Hölker et al. 2004, Viniegra-González and Favela-Torres 2006). However, the presence of an additional carbon source, like in the case of molasses, might have triggered other metabolic processes than stimulating exo-PG production.

Additionally, to demonstrate the importance of an inducer substrate for pectinase production, A. sojae ATCC 20235 was cultivated under conditions of the center point experiments on pure wheat bran and the obtained enzyme activity was about five times lower in comparison to the highest activity obtained with sugar beet pulp as inducer substrate (data not shown). This result strongly favored utilization of pectin-rich inducer substrates, such as sugar beet pulp, in SSF process for pectinolytic enzyme production.

The factor inoculum size had no significant effect on PG production. Based on this fact, in the optimization part of this study the inoculum size was fixed at $2 \times 10^{7}$ total spores, which is close to the level of the center point experiments where maximum PG activity was obtained.

The significance of the factor temperature is known due to its great influence on microbial metabolic activity. Fungi can grow over a wide range of temperatures $\left(20-55^{\circ} \mathrm{C}\right)$, but optimal temperature for growth can differ from that of product formation (Bhargav et al. 2008). The first screening step provided a survey of temperature ranges and highest PG activity was obtained at the center points incubating at $28^{\circ} \mathrm{C}$. Further investigation of this factor was done during the optimization of process parameters.

Due to the exclusion of several experiments resulting in no growth and consequently in no PG production, this first screening investigation provided only an indication for identification of significant factors and their ranges. Therefore, another screening investigation was performed focusing on the most important factors affecting exo-PG activity, $\mathrm{HCl}$ concentration and the inducer substrates apple pomace and sugar beet pulp (Table 2). Moreover, the effect of the inducer substrate concentration on PG production was explored, and also the factor incubation time was further investigated using full factorial design $\left(R^{2} / Q^{2}\right.$ 0.94/0.73). Even though level of $\mathrm{HCl}$ concentration was reduced in the second screening investigation, the applied high level of $0.22 \mathrm{M}$ $\mathrm{HCl}$ in combination with high sugar beet pulp concentration inhibited also fungal growth totally (Table 2 , trial 8 and 16). These trials have been excluded for analysis. The ANOVA results indicated that both inducer substrates as well as their concentration and, as previously determined, the concentration of $\mathrm{HCl}$ significantly influenced exo-PG activity in the crude extracts. Furthermore, the interactions of the inducer concentration/time and $\mathrm{HCl}$ concentration/time had a significant effect on enzyme activity, too. Highest PG activity of $374.5 \mathrm{U} / \mathrm{g}$ was obtained applying $10 \%$ sugar beet pulp as inducer substrate in the medium wetted with $0.22 \mathrm{M} \mathrm{HCl}$ after 5.5 days incubation. Utilization of sugar beet pulp as inducer substrate resulted in higher PG activity in comparison to apple pomace, with the exception of those experiments where fungal growth was inhibited. Due to the fact, that the moisture content of these two inducer substrate differed strongly, this affected also the total amount of solid substrate in the SSF process as well as other significant process parameters. The moisture level in SSF systems is very important (Raimbault 1998). High moisture levels decrease the substrate porosity and hence, reduce the oxygen transfer. While low moisture contents may limit the bioavailability of nutrients and increase the accumulation of heat.

Therefore, experiments were conducted comparing PG production with both inducer substrates at similar moisture levels, which was achieved by freeze-drying apple pomace or increasing the moisture content in sugar beet pulp (data not shown). Higher PG activity was obtained utilizing sugar beet pulp, which was chosen as inducer substrate for further optimization investigations. Moreover, longer incubation time indicated further increase of PG activity, which was considered for optimization of this parameter. In addition, further $\mathrm{HCl}$ concentrations were tested in the range from $0.175 \mathrm{M}$ to $0.2 \mathrm{M}$, which resulted in a positive effect on PG production applying $\mathrm{HCl}$ concentrations of about $0.2 \mathrm{M}$ (data not shown). The combination of a cultivation medium including predominantly wheat bran and applying the moisture level with $0.2 \mathrm{M} \mathrm{HCl}$ concentration was already demonstrated for enhanced microbial enzyme production by filamentous 
fungus in SSF (Fernandez-Lahore et al. 1997). Therefore, the $\mathrm{HCl}$ concentration was fixed at $0.2 \mathrm{M}$ for further optimization experiments.

Summarizing the screening investigations identified sugar beet pulp as potential inducer substrate for PG production in combination with wheat bran and adjusting the moisture level with $0.2 \mathrm{M} \mathrm{HCl}$. Inoculum size in terms of spore concentration had no significant effect on exo-PG activity and was fixed at $2 \times 10^{7}$ total spores.

\section{Optimization of PG production by A. sojae ATCC 20235}

The first optimization step focused on identification of optimal medium composition investigating the inducer substrate concentration and the moisture level in the medium using a complemented D-optimal design (Table 3). Adjusting the moisture level with $0.2 \mathrm{M} \mathrm{HCl}$ influenced water activity and acidity of the fermentation system by varying the factor moisture level. In general, a variable moisture level (as an independent parameter) may seem disadvantageous due to its effect in changing the total reaction volume. A change in the total reaction volume further affects both substrate volume in solid-state cultivation and enzyme concentration obtained after enzyme leaching. The optimal setting of the moisture content factor for cultivation of microorganisms in solid-state cultivation processes is highly dependent upon water-binding properties of the substrate, and the formation of products, such as enzymes, is markedly affected by the moisture content in SSF systems (Prior et al. 1992). Therefore, this factor had to be optimized for PG production by $A$. sojae in the present SSF system.

The original experimental set-up (trial 1 - 11) of the response surface modeling included an inducer concentration range from $10-35 \%$ and a moisture level range from $85-135 \%$. Highest enzyme activity was achieved at high level of moisture and high inducer substrate concentration. Thus, further increase of moisture level and inducer substrate concentration seemed to be promising for higher PG production. The design was complemented by trial $12-18$, including higher factor ranges up to $65 \%$ inducer concentration and 165\% moisture level, which created the D-optimal design for response surface modeling.

Trial 16 was detected as outlier and was excluded from optimization analysis. Evaluation of the experimental data identified a sound model quality $\left(R^{2} / Q^{2} 0.972 / 0.942\right)$. The value of adjusted $R^{2}(0.962)$ was also very high, indicating high significance of the model. Moreover, the lack of fit (LoF) test $(p=0.087)$ pointed in the direction of a valid model. According to the ANOVA results both factors, inducer concentration $\left(\mathrm{X}_{\mathrm{S}}\right)$ and moisture level $\left(\mathrm{X}_{\mathrm{M}}\right)$, were identified as significant factors, as well as their interaction $\left(\mathrm{X}_{\mathrm{S}} \mathrm{X}_{\mathrm{M}}\right)$ and the quadratic term of the variable inducer concentration $\left(\mathrm{X}_{\mathrm{S}}^{2}\right)$. The response variable may be approximated by the following model equation that expressed exo-PG activity in terms of coded factors:

$$
\begin{aligned}
\text { exo-PG activity }=427.04- & 174.56 \mathrm{X}_{\mathrm{S}}+146.44 \mathrm{X}_{\mathrm{M}} \\
& -90.35 \mathrm{X}_{\mathrm{S}} \mathrm{X}_{\mathrm{M}}-279.46 \mathrm{X}_{\mathrm{S}}{ }^{2}
\end{aligned}
$$

The contour plot obtained from the second-order model is presented in Figure 1.

High PG activities were obtained at trial 4 and 18 using 35\% sugar beet pulp as inducer substrate. Prediction for high PG activity values was obtained for inducer concentrations of 15 to $34 \%$ and moisture levels of 157 to $165 \%$ applied by $0.2 \mathrm{M} \mathrm{HCl}$ (Figure 1). Highest PG activity of $613 \mathrm{U} / \mathrm{g}$ was predicted at an inducer concentration of $25 \%$ and a moisture level of $160 \%$. Therefore, an experimental trial including the predicted optimal conditions for PG production, as well as a slightly higher inducer concentration of $30 \%$ closer to the highest results of the optimization experiments were tested. The media were wetted at $160 \%$ with $0.2 \mathrm{M} \mathrm{HCl}$ and cultivation was performed at $28^{\circ} \mathrm{C}$ for 5 days. Under the predicted optimal conditions $634.0 \pm 44.6 \mathrm{U} / \mathrm{g}$ PG activity was obtained which is very close to the predicted result. This represented a very good correlation between the experimental data and the predicted value of the PG activity indicating a good fit of the model. Nevertheless, using $30 \%$ of inducer substrate in the medium resulted in a slightly higher PG activity of $648 \pm 22.3 \mathrm{U} / \mathrm{g}$. The first optimization step provided an optimized medium composition of wheat bran and sugar beet pulp in the ratio $70: 30$, wetted at $160 \%$ with $0.2 \mathrm{M} \mathrm{HCl}$. The combination of wheat bran and sugar beet pulp in optimized ratio is essential for a productive SSF process by $A$. sojae ATCC 20235. Extracting water soluble proteins and carbohydrates from media blanks containing pure wheat bran or the optimized ratio of wheat bran and sugar beet pulp, yielded higher soluble protein content and higher total soluble carbohydrate concentration in the extract of the mixture with sugar beet pulp (data not shown). This indicated that besides stimulation of pectinolytic enzyme production, the presence of sugar beet pulp as inducer substrate increased also the amount of soluble proteins and carbohydrates available for the fungal metabolism.

The second optimization investigation focused on the process parameters incubation temperature and time. The screening results demonstrated further increase of PG activity at longer incubation times. The original experimental set-up included a time range from 5 to 7 days and a temperature range from 26 to $34^{\circ} \mathrm{C}$ (Table 4, trial 1 - 11). Due to the tendency of further increase of PG activity at longer cultivation times the experimental setup was complemented by 3 additional runs with 8 days of incubation time (Table 4, trial $12-14$ ). Evaluation of 


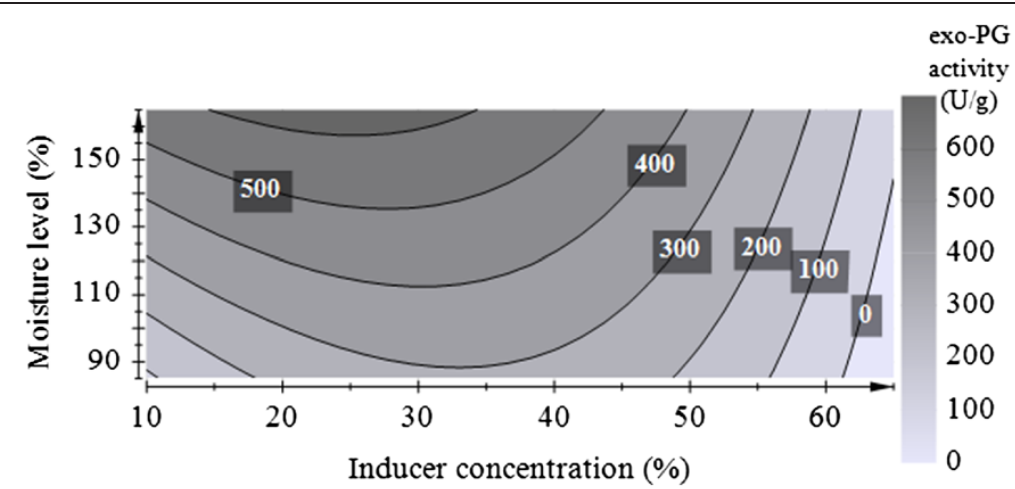

Figure 1 Response surface plot for PG activity as a function of moisture level and inducer concentration obtained by A. sojae ATCC 20235 (medium optimization with D-optimal design).

the experimental data upon removal of insignificant model terms identified a sound model quality $\left(R^{2} / Q^{2}\right.$ 0.948/0.869). Also the LoF test $(p=0.73)$ strongly pointed in the direction of a valid model. According to the ANOVA results both variables, time $\left(\mathrm{X}_{\mathrm{t}}\right)$ and temperature $\left(\mathrm{X}_{\mathrm{T}}\right)$, were identified as significant factors, as well as their interaction $\left(\mathrm{X}_{\mathrm{t}} \mathrm{X}_{\mathrm{T}}\right)$ and the quadratic term of the variable temperature $\left(\mathrm{X}_{\mathrm{T}}^{2}\right)$. The response variable may be approximated by the following model equation that expressed exo-PG activity in terms of coded factors:

$$
\begin{aligned}
\text { exo-PG activity }=700.17 & +126.51 \mathrm{X}_{\mathrm{t}}-65.80 \mathrm{X}_{\mathrm{T}} \\
& +44.40 \mathrm{X}_{\mathrm{t}} \mathrm{X}_{\mathrm{T}}-264.22 \mathrm{X}_{\mathrm{T}}{ }^{2}
\end{aligned}
$$

Maximal exo-PG activity of $847.3 \mathrm{U} / \mathrm{g}$ was obtained after 8 days at $30^{\circ} \mathrm{C}$ (Table 4 , trial 13). The contour plot seen in Figure 2 was constructed from the model for exo-PG activity and demonstrates that high PG activity at different cultivation times is given at the temperature scale around $30^{\circ} \mathrm{C}$. However, the results also strongly indicated further increase of PG activity at longer incubation times. Therefore, further investigation on the factor cultivation time was done to determine the optimal conditions for PG production by A. sojae ATCC 20235 in SSF. Incubation temperature was fixed at $30^{\circ} \mathrm{C}$ and cultivation was performed over a period of nine days harvesting daily samples from day 5 till day 9 (Figure 3). According to the results obtained between five to nine days, the maximum of PG activity was achieved at the 8th day of cultivation with $909.5 \pm 2.7 \mathrm{U} / \mathrm{g}$. Comparing this value with PG activity obtained during the optimization investigation at trial 13 with $847.3 \mathrm{U} / \mathrm{g}$, the variation is below $7 \%$ which indicated also a good reproducibility. At the peak of enzyme production also a high specific activity of $180.0 \pm 6.8 \mathrm{U} / \mathrm{mg}$ protein was obtained. The maximal productivity of $128.9 \mathrm{U} / \mathrm{g} / \mathrm{d}$ was achieved after six days, it slightly decreased to $112.3 \pm 0.3 \mathrm{U} / \mathrm{g} / \mathrm{d}$ at the 8th day of SSF. Only the amount of total protein in the crude extract was further increasing over the time. With regard to previous work (Heerd et al. 2012), where the potential of this strain as PG producer in SSF was presented utilizing a mixture of wheat bran and dried orange peel wetted at $120 \%$ with $0.2 \mathrm{M} \mathrm{HCl}$, the maximum in exo-PG activity was 10.9 times increased by this optimization, measuring both extracts under the same enzyme assay conditions described in the present

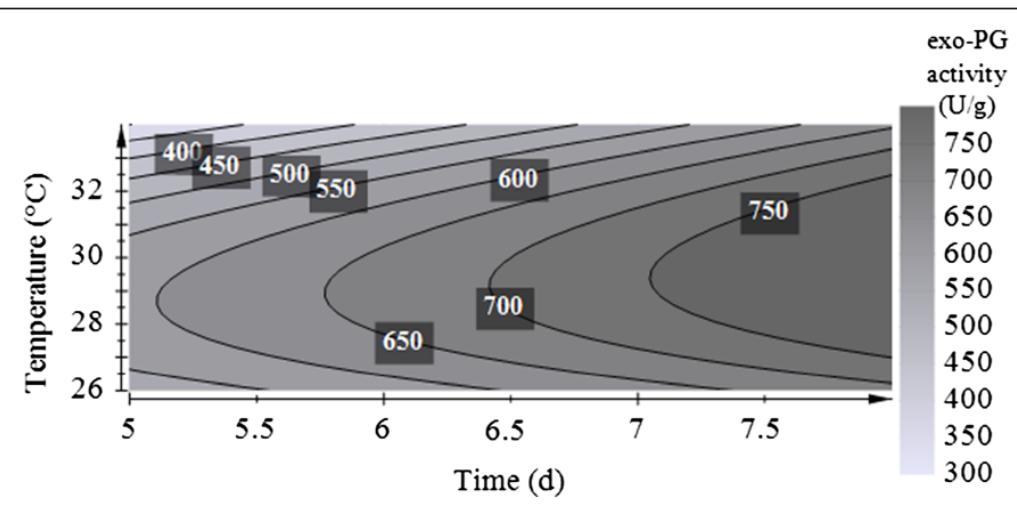

Figure 2 Response surface plot for PG activity as a function of temperature and time obtained by A. sojae ATCC 20235 (process optimization with D-optimal design). 


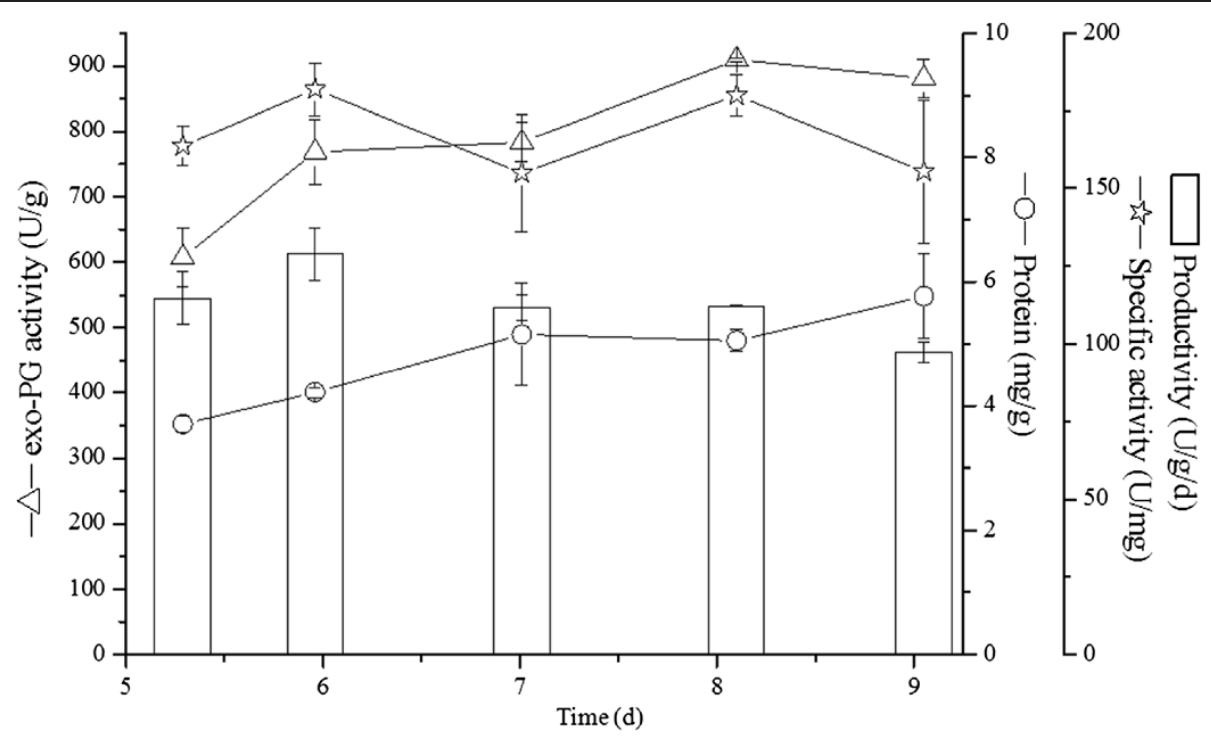

Figure 3 Solid-state fermentation profile of $A$. sojae ATCC 20235 utilizing optimal conditions for exo-PG production.

study. Productivity determined at the peak of enzyme activity was 6.7 fold increased after optimization.

\section{PG production by A. sojae CBS 100928 in SSF}

Prior to this statistical optimization study a screening on different inducer substrates was performed and maximal exo-PG activity was obtained with sugar beet pulp (data not shown). Thus, the optimized medium for PG production by $A$. sojae ATCC 20235 , which contained wheat bran and sugar beet pulp in the ratio $70: 30$, wetted with $0.2 \mathrm{M}$ $\mathrm{HCl}$, provided the basis medium for optimizing enzyme production by A. sojae CBS 100928.

Table 5 presents the results obtained for exo-PG activity in the full factorial design $\left(R^{2} / Q^{2} 0.97 / 0.84\right)$ with three variables studied: moisture level, temperature and cultivation time. The screening data indicated that high values of enzyme activity were obtained at incubation times of six to eight days in combination with higher moisture levels and incubation temperature of $30^{\circ} \mathrm{C}$. Maximum exo-PG activity of $108.1 \pm 5.9 \mathrm{U} / \mathrm{g}$ was achieved at the center point trials at $30^{\circ} \mathrm{C}$. Therefore, the temperature was fixed at $30^{\circ} \mathrm{C}$ and conditions of moisture level and cultivation time were further optimized for enhanced enzyme production.

\section{Optimization of PG production by A. sojae CBS 100928}

Table 6 shows the optimization results obtained for exo-PG activity in CCF design with the two studied variables moisture level and time. Evaluation of the experimental data upon removal of insignificant model terms identified a sound model quality $\left(R^{2} / Q^{2} 0.97 / 0.815\right)$. Also the LoF test $(p=0.485)$ pointed in the direction of a valid model.
According to the ANOVA results both factors, moisture level $\left(X_{M}\right)$ and time $\left(X_{t}\right)$, were identified as significant factors, as well as their interaction $\left(\mathrm{X}_{\mathrm{M}} \mathrm{X}_{\mathrm{t}}\right)$ and the quadratic term of the variable moisture level $\left(\mathrm{X}_{\mathrm{M}}^{2}\right)$. The response variable may be approximated by the following model equation that expressed exo-PG activity in terms of coded factors:

$$
\begin{aligned}
\text { exo-PG activity }=102.78 & -11.52 \mathrm{X}_{\mathrm{M}}+13.45 \mathrm{X}_{\mathrm{t}} \\
+ & 9.50 \mathrm{X}_{\mathrm{M}} \mathrm{X}_{\mathrm{t}}-21.73 \mathrm{X}_{\mathrm{M}}{ }^{2}
\end{aligned}
$$

The contour plot obtained from the second-order model is presented in Figure 4, where high enzyme activity was predicted at moisture levels of 138 to $160 \%$ and incubation times from 7.5 to 8 days. Optimal conditions for PG production in SSF by A. sojae CBS 100928 were similar to the optimized conditions of $A$. sojae ATCC 20235. Maximal PG activity in optimization trials was obtained in trail 8, wetting the substrate at $150 \%$ with $0.2 \mathrm{M}$ $\mathrm{HCl}$ and incubating for 8 days at $30^{\circ} \mathrm{C}$.

Validation experiments were conducted at the predicted optimal point (conditions of trail 8) and experiments applying a moisture level of $160 \%$, which represented the optimized conditions for the other strain. The predicted enzyme activity under optimal conditions was $116.3 \mathrm{U} / \mathrm{g}$ and achieved was an exo-PG activity of $131.9 \pm 6.9 \mathrm{U} / \mathrm{g}$, which indicated a good compatibility of the model with the experimental results. PG production at a moisture level of $160 \%$ was slightly lower with $118.1 \pm 1.2 \mathrm{U} / \mathrm{g}$. Hence, optimized conditions for exo-PG production by A. sojae CBS 100928 in SSF utilizing a mixture of wheat bran and sugar beet pulp in the ratio 70:30 as substrate 


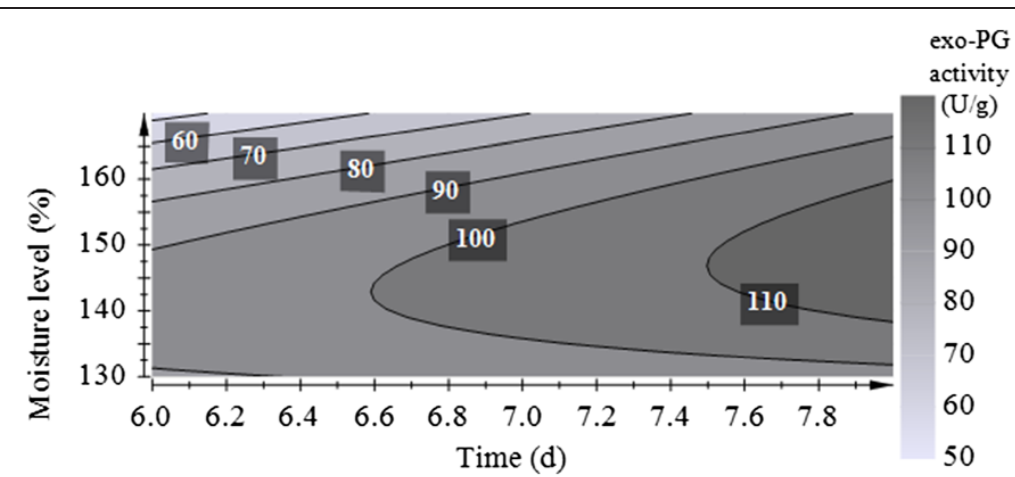

Figure 4 Response surface plot for PG activity as a function of moisture level and time obtained by A. sojae CBS 100928 (optimization with CCF design).

were determined at a moisture level of $150 \%$ applied by $0.2 \mathrm{M} \mathrm{HCl}$ after 8 days incubation at $30^{\circ} \mathrm{C}$.

\section{Comparison under optimized conditions}

Comparing enzyme activities obtained under optimized conditions, 6.9 times higher pectinase activity was achieved by $A$. sojae ATCC 20235 . This result confirmed previous findings of highest pectinase production by $A$. sojae ATCC 20235 in SSF (Heerd et al. 2012). Highest fungal polygalacturonic acid degrading exo-enzyme activity (480 U/g) measured with the arsenomolybdate reagent in SSF extracts was produced on wheat bran by $A$. carbonarius (Jacob 2009). This enzyme yield was 1.9 times increased using A. sojae ATCC 20235 in SSF under optimized conditions in this study. Crude extracts of $A$. sojae ATCC 20235 and A. sojae CBS 100928 obtained under optimized conditions for pectinolytic enzyme production were analyzed by polyacrylamide gel electrophoresis under denaturing conditions. Results are presented in Figure 5. The profile of both fungal strains presented two remarkable bands between the protein standards of $46 \mathrm{kDa}$ and $58 \mathrm{kDa}$. Especially noticeable is the increase of these bands in the extract of $A$. sojae CBS 100928 after optimizing the pectinolytic enzyme production in comparison to previous results of Heerd et al. (2012). Comparing these bands to the protein profile of commercial pectinase preparations suggested the presence of a protein band at the same level of the lower thick band in Fructozym P (Erbslöh Geisenheim AG), which is a concentrated pectinolytic enzyme preparation for pectin degradation in fruit mash and fruit juice.

The protein content of the extracts was also fractionated by native electrophoresis so as to preserve enzyme activity (Figure 6). It has to be recalled that the active fractions (bands or zones) observed in this case are not directly related to the molecular mass since separation in native gel is related to charge/size. This makes the information gathered in Figure 6 difficult to compare with the profiles observed in Figure 5. Nevertheless, it can be noticed that the extracts of the different strains induced a distinctive pattern in the zymogram. In contrast to previous findings (Heerd et al. 2012), only one active zone was observed in the extract produced under optimized conditions by A. sojae CBS 100928. Based on the results of this study SSF process conditions and media design significantly influence protein pattern produced in SSF and hence enzyme production. Moreover, comparing the electrophoresed gel with the substratecontaining agar plate in Figure 6 revealed the presence of protein bands in the extracts of both fungal strains, which did not produce active zones on polygalacturonic acid sodium salt as substrate. This indicated the production of other enzyme types under the optimized conditions. The commercially available enzyme preparations from Sigma-Aldrich and Erbslöh Geisenheim AG were produced by Aspergillus spp. in SmF and presented protein patterns with several active zones (Figure 6). Commercial pectinase preparations usually contain mixtures of various pectinolytic enzymes, which are additionally associated with cellulolytic, proteolytic and other species of enzymes apart from the main pectinases (Del Cañizo et al. 1994). Thus, comparing the electrophoresed gel with the substratecontaining agar plate in Figure 6 also revealed the presence of protein bands in the commercial pectinase preparations, which did not produce active zones. The composition of enzyme sets differ significantly between fungal species and this is also observed for the subset of pectinolytic enzymes (Benoit et al. 2012). The difference in enzyme production between SSF and SmF was already discussed in a recent study (Kumar et al. 2011).

\section{Comparison of enzyme profiles}

Investigation of pectinolytic enzyme sets was performed on enzyme extracts obtained from both strains under optimized conditions for PG production applying a moisture level of $160 \%$ (Table 7). The difference in exo-PG activity in comparison to the optimization results might be caused by utilization of sugar beet pulp from another 

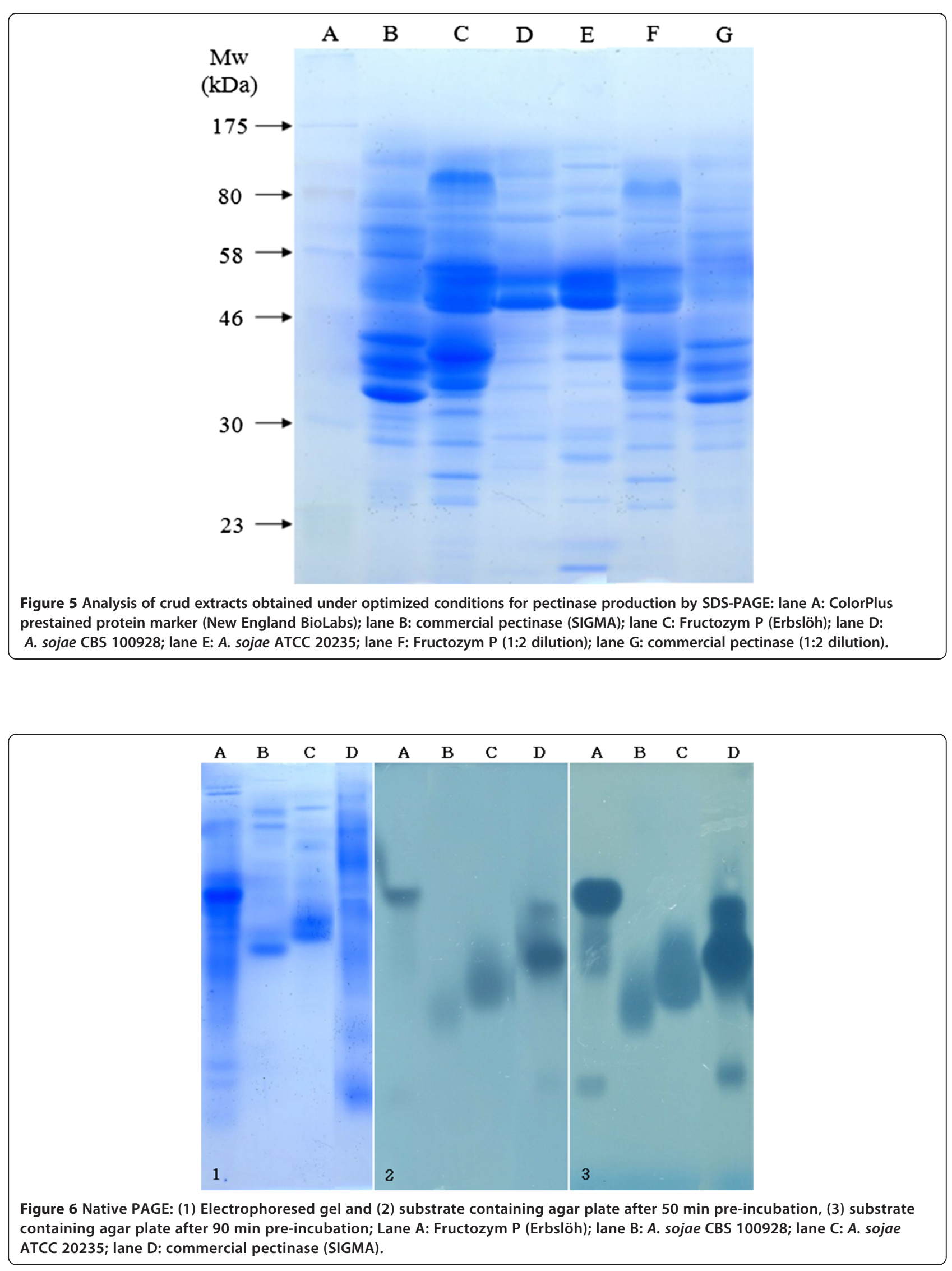
Table 7 Comparison of enzyme activities obtained under the same cultivation conditions

\begin{tabular}{|c|c|c|c|c|c|c|}
\hline \multirow[t]{2}{*}{ Microorganism } & \multirow{2}{*}{$\begin{array}{c}\text { PG activity }(\mathrm{U} / \mathrm{g}) \\
\text { exo }\end{array}$} & \multirow{2}{*}{$\begin{array}{c}\text { Specific activity (U/mg) } \\
\text { exo-PG }\end{array}$} & \multicolumn{2}{|c|}{$\begin{array}{l}\text { endo-activity }(\mathrm{U} / \mathrm{mL}) \text { at } \\
1 \mathrm{U} / \mathrm{mL} \text { exo-PG activity }\end{array}$} & \multirow{2}{*}{$\begin{array}{l}\text { PMG activity }(\mathrm{U} / \mathrm{g}) \\
\text { exo }\end{array}$} & \multirow[t]{2}{*}{$\begin{array}{l}\text { Proteolytic activity } \\
\left(\log _{10} \mathrm{~mm}^{2}\right)\end{array}$} \\
\hline & & & PG & PMG & & \\
\hline A. sojae ATCC 20235 & $632.7 \pm 61.7$ & $133.7 \pm 10.2$ & $1.08 \pm 0.07$ & $0.87 \pm 0.08$ & $30.1 \pm 2.4$ & $2.50 \pm 0.05$ \\
\hline A. sojae CBS 100928 & $133.2 \pm 12.1$ & $54.6 \pm 7.7$ & $1.13 \pm 0.01$ & $0.99 \pm 0.01$ & $20.7 \pm 1.9$ & $2.12 \pm 0.02$ \\
\hline
\end{tabular}

The observed values of enzyme activities were the mean values of duplicates with standard deviation (mean \pm SD).

harvest batch. This could imply that the beet root was harvested from another producer region and also at another season. These factors would strongly effect the composition of beet roots, e.g. by varying the sugar content, and hence the type of inducer substrate.

Exo-PMG activity obtained by cultivation of $A$. sojae ATCC 20235 was higher compared to A. sojae CBS 100928. In comparison to results of previous work (Heerd et al. 2012), PMG activity in the extract of A. sojae ATCC 20235 slightly decreased by $10 \%$, while the PMG activity in the extract of A. sojae CBS 100928 increased by $25 \%$ after optimizing SSF conditions. These changes are irreducible in contrast to the change of exoPG activity, which is confirming that primarily the exopectinase activity degrading polygalacturonic acid was increased by this optimization. Furthermore, the obtained extracts of both strains were diluted to $1 \mathrm{U} / \mathrm{mL}$ of exo-PG activity to compare the ratio of exo-PG activity and endopectinolytic activities. The values given in Table 7 show an almost balanced ratio of exo- to endo-PG activity for both strains with a slightly higher endo-PG activity. The ratio of exo-PG activity to endo-PMG activity is also balanced in the extract of $A$. sojae CBS 100928. The endo-PMG activity in the extract of A. sojae ATCC 20235 is slightly lower than the exo-PG activity. The SSF process optimization for enhanced exo-PG production increased also the endo-enzyme activities of both strains in comparison to previous results (Heerd et al. 2012). Comparing endo-PG with endo-PMG activities, higher activity of polygalacturonic acid degrading enzymes was produced in the extracts of both strains.

In addition to pectinolytic activities also the proteolytic activity was determined. Activity of proteases in the extract of $A$. sojae ATCC 20235 was higher than in the extract of $A$. sojae CBS 100928. In comparison to previous results, no significant changes in proteolytic activity were observed (Heerd et al. 2012), which indicated that the process optimization had no influence on proteolytic enzyme production.

Comparing present results with reported PG activities in the literature, previous optimization studies with A. sojae ATCC 20235 applying crushed maize wetted with a nutrient solution, which resembled a surface cultivation, yielded $29.1 \mathrm{U} / \mathrm{g}$ exo-PG activity (Ustok et al. 2007). PG production by $A$. sojae ATCC 20235 was dramatically increased under solid-state conditions in the present study optimizing the SSF process and utilizing a cost-efficient medium.

Utilization of agro-based products in SmF and using a mutant of this strain, generated by treatment with UV radiation, yielded an enzyme activity of $145.4 \mathrm{U} / \mathrm{mL}$ in shaking flask cultures (Buyukkileci et al. 2011). The combination of optimizing the fermentation process utilizing agricultural substrates with microbial strain improvement increased dramatically the enzyme yield in SmF. The results of the present optimization study showed already the potential of PG production by the wild type in SSF utilizing agricultural products. The combination with microbial strain improvement might generate a process of PG production which could be attractive for industrial applications.

\section{Conclusions}

PG production by $A$. sojae was optimized applying crude plant compounds, such as wheat bran and sugar beet pulp, as substrate in SSF. The present study demonstrated a great potential for cost-efficient pectinolytic enzyme production by Aspergillus sojae ATCC 20235. Production under optimized conditions in laboratory scale yielded high exo-PG activity and sugar beet pulp was identified as significant pectinase inducer substrate. Utilization of agricultural and agro-industrial by-products developed an attractive sustainable bioprocess for enzyme production.

Optimized pectinolytic enzyme production yield of A. sojae ATCC 20235 was 6.9 times higher in comparison to A. sojae CBS 100928. High enzyme yield obtained by $A$. sojae ATCC 20235 under optimized conditions will be a promising starting point for scale-up and polygalacturonase purification studies.

\section{Competing interests}

The authors declare that they have no competing interests.

\section{Authors' contributions}

$\mathrm{DH}$ designed and performed experiments, analyzed and interpreted the data and wrote the manuscript. SDH supervised progress of experiments and scientific interpretation of the obtained data, and proofread the manuscript. MFL supervised work. All authors read and approved the manuscript.

\section{Acknowledgements}

Financial support of Jacobs University Bremen gGmbH through the project PGSYS / ETB-2008-44 and PGSYS EXCHANGE / FP7-PEOPLE-2010-IRSES is gratefully acknowledged.

Prof. Dr. Canan Tari from İzmir Institute of Technology, İzmir, Turkey, is kindly acknowledged for the supply of the strain A. sojae ATCC 20235. 
The authors would like to thank Döhler GmbH (Neuenkirchen, Germany), Nordzucker AG (Uelzen, Germany) and Bremer Rolandmühle Erling GmbH \& Co. KG (Bremen, Germany) for providing the substrates for pectinolytic enzyme production.

Received: 18 September 2014 Accepted: 9 December 2014 Published: 16 December 2014

\section{References}

Alimardani-Theuil P, Gainvors-Claisse A, Duchiron F (2011) Yeast: An attractive source of pectinases - From gene expression to potential applications: A review. Process Biochem 46:1525-1537

Benoit I, Coutinho PM, Schols HA, Gerlach JP, Henrissat B, de Vries RP (2012) Degradation of different pectins by fungi: correlations and contrasts between the pectinolytic enzyme sets identified in genomes and the growth on pectins of different origin. BMC Genomics 13:321

Bhargav S, Panda BP, Ali M, Javed S (2008) Solid-state fermentation: An overview. Chem Biochem Eng Q 22(1):49-70

Blandino A, lqbalsyah T, Pandiella SS, Cantero D, Webb C (2002) Polygalacturonase production by Aspergillus awamori on wheat in solid-state fermentation. Appl Microbiol Biot 58:164-169

Bradford MM (1976) A rapid and sensitive method for the quantitation of microgram quantities of protein utilizing the principle of protein-dye binding. Anal Bioch 72:248-254

Buyukkileci AO, Tari C, Fernandez-Lahore M (2011) Enhanced production of exo-polygalacturonase from agro-based products by Aspergillus sojae. BioResources 6(3):3452-3468

Del Cañizo AN, Hours RA, Miranda MV, Cascone O (1994) Fractionation of fungal pectic enzymes by immobilized metal ion affinity chromatography. J Sci Food Agric 64:527-531

Fernandez-Lahore MH, Gallego Duaigües MV, Cascone O, Fraile ER (1997) Solid state production of a Mucor bacilliformis acid protease. Rev Argent Microbiol 29:1-6

Heerd D, Yegin S, Tari C, Fernandez-Lahore M (2012) Pectinase enzyme-complex production by Aspergillus spp in sold-state fermentation: A comparative study. Food Bioprod Process 90:102-110

Heerd D, Tari C, Fernández-Lahore M (2014) Microbial strain improvement for enhanced polygalacturonase production by Aspergillus sojae. Appl Microbiol Biot 98(17):7471-7481

Heerikhuisen M, Van den Hondel C, Punt P (2005) Aspergillus sojae. In: Gellissen G (ed) Production of recombinant proteins. Novel microbial and eukaryotic expression systems, WILEY-VCH, Weinheim

Hölker U, Höfer M, Lenz J (2004) Biotechnological advanteges of laboratory-scale solid-state fermentation with fungi. Appl Microbiol Biot 64:175-186

Jacob N (2009) Pectinolytic Enzymes. In: Nigam PS, Pandey A (eds) Biotechnology for agro-industrial residues utilization. Springer, Netherlands

Jørgensen TR (2007) Identification and toxigenic potential of the industrially important fungi, Aspergillus oryzae and Aspergillus sojae. J Food Protect 70(12):2916-2934

Kashyap DR, Vohra PK, Chopra S, Tewari R (2001) Applications of pectinases in the commercial sector: a review. Bioresource Technol 77:215-227

Kumar S, Sharma HK, Sarkar BC (2011) Effect of substrate and fermentation conditions on pectinase and cellulase production by Aspergillus niger NCIM 548 in submerged (SmF) and solid state fermentation (SSF). Food Sci Biotechnol 20(5):1289-1298

Laemmli UK (1970) Cleavage of structural proteins during the assembly of the head of bacteriophage T4. Nature 227:680-685

Manchenko GP (1994) Handbook of Detection of Enzymes on Electrophoresis Gels. CRC Press, Boca Raton

Mill PJ, Tuttobello R (1961) The pectic enzymes of Aspergillus niger. Biochem J 79:57-64

Montville TJ (1983) Dual-substrate plate diffusion assay for proteases. Applied Environmental Microbiology 45:200-204

Naidu GSN, Panda T (1998) Production of pectolytic enzymes - a review. Bioprocess Eng 19:355-361

Nandakumar MP, Thakur MS, Raghavarao KSMS, Ghildyal NP (1999) Studies on catabolite repression in solid state fermentation for biosynthesis of fungal amylases. Lett Appl Microbiol 29(6):380-384

Neuhoff V, Arnold N, Taube D, Ehrhardt W (1988) Improved staining of proteins in polyacrylamide gels including isoelectric focusing gels with clear background at nanogram sensitivity using Coomassie Brillant Blue G-250 and R-250. Electrophoresis 9:255-262

Nigam PS, Pandey A (2009) Biotechnology for agro-industrial residues utilization. Springer, Netherlands

Niture SK (2008) Comparative biochemical and structural characterizations of fungal polygalacturonases. Biologia 63(1):1-19

Panda T, Naidu GSN, Sinha J (1999) Multipleresponse analysis of pectinolytic enzymes by Aspergillus niger: a statistical view. Process Biochem 35:187-195

Patil SR, Dayanand A (2006) Optimization of process for the production of fungal pectinases from deseeded sunflower head in submerged and solid-state conditions. Bioresource Technol 97:2340-2344

Prior BA, Du Preez JC, Rein PW (1992) Environmental parameters. In: Doelle HW, Mitchell D, Rolz CE (eds) Solid substrate cultivation. Elsevier Science Publishers LTD, Essex

Raimbault M (1998) General and microbiological aspects of solid substrate fermentation. Electron J Biotech 1(3):1-15

Semenova MV, Sinitsyna OA, Morozova W, Fedorova EA, Gusakov AV, Okunev ON, Sokolova LM, Koshelev AV, Bubnova TV, Vinetskii YP, Sinitsyn AP (2006) Use of preparation from fungal pectin lyase in the food industry. Appl Biochem Micro+ 42(6):598-602

Thomas L, Larroche C, Pandey A (2013) Current developments in solid-state fermentation. Biochem Eng J 81:146-161

Ushijima S, Hayashi K, Murakami H (1982) The current taxonomic status of Aspergillus sojae used in Shoyu fermentation. Agric Biol Chem 46:2365-2367

Ustok FI, Tari C, Gogus N (2007) Solid-state production of polygalacturonase by Aspergillus sojae ATCC 20235. J Biotechn 127:322-334

van den Brink J, de Vries RP (2011) Fungal enzyme sets for plant polysaccharide degradation. Appl Microbiol Biot 91:1477-1492

Viniegra-González G, Favela-Torres E (2006) Why solid-state fermentation seems to be resistant to catabolite repression? Food Technol Biotechnol 44(3):397-406

Yapo BM, Lerouge P, Thibault J-F, Ralet M-C (2007) Pectins from citrus peel dell walls contain homogalacturonan homogenous with respect to lora mass, rhamnogalacturonan I and rhamnogalacturonan II. Carbohyd Polym 69:426-435

\section{doi:10.1186/2193-1801-3-742}

Cite this article as: Heerd et al:: Efficient polygalacturonase production from agricultural and agro-industrial residues by solid-state culture of Aspergillus sojae under optimized conditions. SpringerPlus 2014 3:742.

\section{Submit your manuscript to a SpringerOpen ${ }^{\odot}$ journal and benefit from:}

- Convenient online submission

- Rigorous peer review

- Immediate publication on acceptance

- Open access: articles freely available online

- High visibility within the field

- Retaining the copyright to your article

Submit your next manuscript at $>$ springeropen.com 